\title{
The use of anticoagulants in morbidly obese patients
}

\author{
Justyna Domienik-Karłowicz, Piotr Pruszczyk \\ Department of Internal Medicine and Cardiology with the Center for Diagnosis and Treatment \\ of Venous Thromboembolism, Medical University of Warsaw, Poland
}

\begin{abstract}
Due to its constantly growing incidence, obesity is an increasingly serious social and medical problem. Available data on the use of novel oral anticoagulants in morbidly obese and obese patients are very limited. However, we tried to summarize the available knowledge on the use of anticoagulants in this subpopulation of patients in everyday clinical practice. Studies on the clinical use of anticoagulants provide a poor basis for any adjustment of doses in obese patients as compared to patients with normal body weight. In our opinion, further studies are required in this particular population. (Cardiol J 2016; 23, 1: 12-16)
\end{abstract}

Key words: morbid obesity, obesity, bariatric surgery, anticoagulant drugs, factor Xa inhibitors, heparin

\section{Introduction}

Due to its constantly growing incidence, obesity is an increasingly serious social and medical problem. It is estimated that by the year 2030, patients with obesity will have comprised more than $50 \%$ of the general population while more than $10 \%$ will have been diagnosed with morbid obesity defined as body mass index (BMI) of above $40 \mathrm{~kg} / \mathrm{m}^{2}$ [1]. Limited data are available on the use of novel oral anticoagulants in morbidly obese patients. Incomplete data are available also with regard to the conventional anticoagulants such as low molecular weight heparins or vitamin $\mathrm{K}$ antagonists. Overweight and obese patients are usually either excluded from clinical trials or their participation in such trials is significantly limited.

Therefore, the use of medications in this patient group remains a significant therapeutic challenge. In addition, as shown by pharmacokinetic studies, certain pharmacokinetic parameters such as distribution volume, biological half-life and clearance can be significantly altered in obese patients [2]. As shown by these data, drug dosage in obese patients should depend on both the patient and the drug. In clinical practice, physicians may often find themselves lacking confidence with regard to therapeutic decisions as they are uncertain whether the dose of the drug should be increased proportionally to the body weight or reduced so as to prevent adverse effects.

Thus, we believe that there is a need to summarize the available knowledge on the use of anticoagulants in this subpopulation of patients in everyday clinical practice.

\section{Low molecular weight heparins}

The dosage of low molecular weight heparins depends on the patient's weight; this includes also obese or morbidly obese patients. Safety and efficacy of such doses calculated in this manner were confirmed for individual heparin products: in patients with total body weight of up to $144 \mathrm{~kg}$ $\left(\mathrm{BMI} \leq 48 \mathrm{~kg} / \mathrm{m}^{2}\right)$ for enoxaparin [3], patients with total body weight of up to $190 \mathrm{~kg}\left(\mathrm{BMI} \leq 58 \mathrm{~kg} / \mathrm{m}^{2}\right)$ for dalteparin [4], and patients with total body weight of up to $165 \mathrm{~kg}\left(\mathrm{BMI} \leq 61 \mathrm{~kg} / \mathrm{m}^{2}\right)$ for tin-

Address for correspondence: Justyna Domienik-Karłowicz, MD, Department of Internal Medicine and Cardiology with the Center for Diagnosis and Treatment of Venous Thromboembolism, Medical University of Warsaw, ul. Lindley'a 4, 00-005 Warszawa, Poland, tel: +48 50211 44, fax: +48 2250213 63, e-mail: jdomienik@tlen.pl 
zaparin $[5,6]$. No increased incidence of hemorrhagic complications or recurrent venous thromboembolism was found in the RIETE registry for patients with total body weight of more than $100 \mathrm{~kg}$ (range 100-160 kg) treated with unfractionated or low molecular weight heparin [7]. In addition, negative correlation between total body weight and anti-Xa activity $\left(\mathrm{R}^{2}=0.63\right)$ was demonstrated in obese patients in whom a fixed preventive dose of enoxaparin was recommended [8]. Similar correlations were demonstrated for nadroparin [9]. As shown by these studies, higher prophylactic doses of low molecular weight heparins should be used in patients with obesity [10]. However, it seems justified to measure anti-Xa activity in extremely obese patients.

Moreover, it is worth noticing that the drug can induce thrombocytopenia (heparin-induced thrombocytopenia [HIT]), by an immune-mediated mechanism [11]. The risk of HIT is related to many factors, including obesity, performed surgery (release of cytokines during tissue injury), sex, age, duration of heparin exposure, characteristics of heparin molecule (unfractionated heparin [UFH], low molecular weight heparin [LMWH]), genetic predisposition. It is mediated by IgG antibodies which bind to epitopes on PF4. Then these immune complexes cross-link Fc $\gamma$ receptors on platelets, monocytes, as well as endothelial cells. It results in intense platelet activation, releasing procoagulant rich microparticles, thus activating coagulation cascade and facilitating coagulation (by providing an anionic phospholipid membrane syndrome). Thus, HIT is most frequently associated with thromboembolic complications including deep vein thrombosis, pulmonary embolism, stroke, peripheral artery thrombosis, necrotizing lesions at the heparin injections site [11-13].

Importantly, the risk of HIT is higher after administration of UFH than LMWH to patients after surgery $[11,12]$.

\section{Vitamin $\mathrm{K}$ antagonists}

The effect of obesity on the use of warfarin remains a largely unexamined and academic problem due to the possibilities to effectively monitor the efficacy of treatment. Routledge et al. [14] point out that the key factors affecting the pharmacokinetic properties of warfarin are age followed by body weight.

The study by Wallace et al. [15], including 211 patients with various body weights, determined the percentage of patients achieving international normalized ratio (INR) values within the therapeu- tic range before being discharged from hospital: the obtained ratios were $71.1 \%$ of patients with normal body weight as compared to $42.3 \%$ of patients with obesity and $38 \%$ of patients with morbid obesity. Compared to patients with normal body weight, obese patients, and particularly morbidly obese patients, required more time to achieve therapeutic INR values ( 6 days vs. 8 and 10 days, respectively). Additionally, compared to normal weight, obese and morbidly obese patients were reported to have a decreased initial response to warfarin.

Novel anticoagulants belong to two different classes of the inhibitors of factor X (apixaban, rivaroxaban, edoxaban) and the inhibitors of factor II, or thrombin (dabigatran) [16].

\section{Dabigatran}

Based on the available clinical data and pharmacokinetic properties of the drug, no dose adjustments are required with regard to the patient's body weight (section 5.2 [17]); however, close clinical monitoring is recommended only in the case of patients with body weight of $<50 \mathrm{~kg}$ (section 4.4 [17]).

Nevertheless, it should be noted that Breuer et al. [18], in their article published in NEJM, present a case of a 48-year-old patient with morbid obesity (BMI $44.7 \mathrm{~kg} / \mathrm{m}^{2}$ ) admitted to hospital due to an ischemic stroke during dabigatran treatment (150 mg bid). The peak concentration of dabigatran measured in the patient was as low as $50 \mathrm{ng} / \mathrm{mL}$ ( $4 \mathrm{~h}$ after administration, i.e. at the maximum expected concentration time), which was unambiguously lower than $90 \%$ confidence interval (CI) in the group of patients with average body weight. However, the fact that the patient had received a proton pump inhibitor, which reduced the bioavailability of the drug by $12.5 \%$, should also be taken into account [19]. The authors of the case report concluded that the dose of the drug might have been insufficient for effective treatment of patients with morbid obesity. In their analysis of pharmacokinetic properties of dabigatran from RE-LY study data, Liesenfeld et al. [19] demonstrated that obesity affects the drug distribution volume, increasing it by $0.77 \%$ per each kilogram of body weight above the median value $(80 \mathrm{~kg})$. At the same time, the authors pointed out that the body weight had no effect on the area under the concentration vs. time curve $\left(\mathrm{AUC}_{\mathrm{ss}}\right)$. The authors concluded that no dosage changes are required depending on patient's weight [19].

Lachant et al. [20] reported a patient with a history of bariatric surgery undergoing dabigatran 
treatment (150 mg twice daily). According to the authors, anatomical changes due to surgery made it impossible to efficiently absorb the drug.

In their study including 1,826 obese patients (32.1\% of the overall study population), Eriksson et al. [21] observed similar (statistically insignificant, $0.08 \%$ reduction) risk of adverse endpoints (venous thromboembolism, death due to venous thromboembolism, significant bleeding) in patients receiving dabigatran $220 \mathrm{mg}$ once daily vs. enoxaparin in primary prevention in patients subjected to orthopedic surgeries. Of note are the significantly better results obtained with dabigatran $220 \mathrm{mg}$ once daily vs. enoxaparin $40 \mathrm{mg}$ once daily in patients with obesity (33\% relative risk reduction) and patients with normal body weights (52\% relative risk reduction).

Could an increased dosage of dabigatran provide better therapeutic effects in obese patients? According to the current summary of product characteristics, obesity is not an indication for increasing the dosage of the drug [17].

\section{Rivaroxaban}

According to the summary of product characteristics, there is no need to modify the dosage for extreme body weights, including body weights of $>120 \mathrm{~kg}$. Thus, obesity was not an indication for an increase in drug dosage [22].

Kubitza et al. [23] compared the safety profile, pharmacokinetics and pharmacodynamics of rivaroxaban in groups of patients with body weights of $<50 \mathrm{~kg}, 70-80 \mathrm{~kg}$, and $>120 \mathrm{~kg}$ but $<150 \mathrm{~kg}$. Slightly shorter elongations of prothrombin times were observed in patients with increased body weights. The increased body weight did not significantly disturb the pharmacokinetics and pharmacodynamics of the drug. This was most probably due to the low volume of distribution of rivaroxaban. According to the results of the study, no dose adjustments are required in patients with body weights of up to $150 \mathrm{~kg}$.

Friedman et al. [24] compared the efficacy of anticoagulation treatment with rivaroxaban (occurrence of asymptomatic/symptomatic deep vein thrombosis, pulmonary embolism, bleedings and other adverse effects in orthopedic surgery patients with BMI $>40 \mathrm{~kg} / \mathrm{m}^{2}$ and $<40 \mathrm{~kg} / \mathrm{m}^{2}$ [subanalysis of a group of 12,355 patients]). The authors observed no differences in the incidence rates of aforementioned disorders.

Mahlmann et al. [25] described a case of a morbidly obese patient after bariatric surgery in whom rivaroxaban was used due to the high risk of venous thromboembolism. Rivaroxaban levels were determined $3 \mathrm{~h}, 6 \mathrm{~h}, 12 \mathrm{~h}$, and $24 \mathrm{~h}$ after administration to obtain a typical pharmacokinetic profile. The authors concluded that no adjustments of rivaroxaban treatment were required in a patient after bariatric surgery. Another clinical case report was published by Safouris et al. [26] who suggested a better pharmacokinetic profile of rivaroxaban as compared to dabigatran in an obese patient with no comorbid diabetes. However, it should be underlined that rivaroxaban, similarly to dabigatran, is mostly absorbed in upper gastrointestinal tract including stomach and small intestinum, therefore gastrectomy or sleeve surgery can potentially affect their absorption.

\section{Edoxaban}

Edoxaban is a direct and reversible inhibitor of factor Xa. Hokusai-VTE study compared the efficacy and safety of an enoxaparin/unfractionated heparin lead-in followed by edoxaban $60 \mathrm{mg}$ once daily vs. standard of care (enoxaparin/unfractionated heparin lead-in followed by warfarin) in the treatment of symptomatic venous thromboembolism, with a primary efficacy outcome of recurrent symptomatic venous tromboembolism and a primary safety outcome of major or clinically relevant bleeding [27]. In this study including 611 (14.8\%) patients with body mass $>100 \mathrm{~kg}$ in the group treated with edoxaban and 654 (15.9\%) patients with body mass $>100 \mathrm{~kg}$ in the group treated with warfarin, similar effects in both relative efficacy and safety were observed [27].

According to the available data, there is no need to modify the dosage for extreme body weights, including body weights of $>100 \mathrm{~kg}$. Thus, obesity was not an indication for an increase in drug dosage $[27,28]$.

\section{Apixaban}

According to the summary of product characteristics (5.2. Pharmacodynamic properties [29]), body weight of $>120 \mathrm{~kg}$ was associated with the exposure to medicinal product being reduced by ca. $30 \%$, while body weight of $<50 \mathrm{~kg}$ was associated with the exposure to medicinal product being increased by ca. $30 \%$ as compared to patients with body weights in the range of $65-85 \mathrm{~kg}$ [29]. Upreti et al. [30] determined both plasma and urine levels of apixaban, as well as measured anti-Xa activity following administration of a single $10 \mathrm{mg}$ dose of apixaban to 54 healthy volunteers (18 subjects with body weights of $\leq 50 \mathrm{~kg}, 18$ subjects with body weights 
of $65-85 \mathrm{~kg}$, and 19 subjects with body weights of $\geq 120 \mathrm{~kg}$ [120-175 kg] and BMI $\geq 30 \mathrm{~kg} / \mathrm{m}^{2}$, indicative of obesity). Maximum blood levels of the drug and areas under the concentration vs. time curve $\left(\mathrm{AUC}_{(0, \propto)}\right)$ were found to be respectively $31 \%$ (90\% CI 18-41\%) and 23\% (90\% CI 9-35\%) lower in obese patients. The time to maximum concentration of apixaban in the group of obese patients was similar to that in the reference group and amounted to $3.90 \mathrm{~h}(1.00-6.00)$. In conclusion, the authors do not recommend any adjustments of apixaban dose depending on body weight $[30,31]$. In a clinical study, Pandit et al. [31] found that apixaban is more effective than low molecular weight heparin in obese patients (OR $0.54, \mathrm{p}=0.01$ ) with the lower dose of dabigatran $(150 \mathrm{mg}$ ) being less effective $(\mathrm{OR} 1.81, \mathrm{p}=0.02)$.

\section{Conclusions}

Studies on clinical use of anticoagulants provide no basis for any adjustment of doses in obese patients as compared to patients with normal body weight $[10,16]$. In our opinion, however, further studies are required in this specific population. Therefore, an increased caution should be exercised when using these drugs, particularly in morbidly obese patients.

Importantly, data on the use of anticoagulants in patients after various types of bariatric surgery are based on individual case reports only, and therefore, special attention should be paid when using oral anticoagulants, particularly after surgeries interfering with food absorption, until appropriate guidelines are established. Since no methods of new oral anticoagulants monitoring are widely available, bariatric surgery may affect new oral anticoagulants absorption and clinical experience in this population is highly limited; so we prefer anticoagulation with INR adjusted vitamin $\mathrm{K}$ antagonists in this group.

Conflict of interest: Justyna Domienik-Karłowicz - no conflict of interests; Piotr Pruszczyk - lectures fees and advisory boards for Bayer, Boehringer Ingelheim, Bristol-Myers Squibb, Pfizer.

\section{References}

1. Kelly T, Yang W, Chen CS, Reynolds K, He J. Global burden of obesity in 2005 and projections to 2030. Int J Obes (Lond), 2008; 32: 1431-1437. doi: 10.1038/ijo.2008.102.

2. Jaźwińska -Tarnawska E, Kubiak E, Wiela-Chojeńska A. Differences in pharmacokinetics in obesity. Do obese persons require changes in therapeutic schemes? Adv Clin Exp Med., 2006; 15: 669-676.
3. Sanderink GJ, Le Liboux A, Jariwala N et al. The pharmacokinetics and pharmacodynamics of enoxaparin in obese volunteers. Clin Pharmacol Ther, 2002; 72: 308-318.

4. Smith J, Canton EM. Weight-based administration of dalteparin in obese patients. Am J Health Syst Pharm, 2003; 60: 683-687.

5. Hainer JW, Barrett JS, Assaid CA et al. Dosing in heavy-weight/ /obese patients with the LMWH, tinzaparin: A pharmacodynamic study. Thromb Haemost, 2002; 87: 817-823.

6. Spinler SA, Inverso SM, Cohen M et al. Safety and efficacy of unfractionated heparin versus enoxaparin in patients who are obese and patients with severe renal impairment: Analysis from the ESSENCE and TIMI 11B studies. Am Heart J, 2003; 146: 33-41.

7. Barba R, Marco J, Martin-Alvarez $\mathrm{H}$ et al. The influence of extreme bodyweight on clinical outcome of patients with venous thromboembolism: Findings from a prospective registry (RIETE). J Thromb Haemost, 2005; 3: 856-862,

8. Frederiksen SG, Hedenbro JL, Norgren L. Enoxaparin effect depends on body-weight and current doses may be inadequate in obese patients. Br J Surg, 2003; 90: 547-548.

9. Heizmann M, Baerlocher GM, Steinmann F et al. Anti-Xa activity in obese patients after double standard dose of nadroparin for prophylaxis. Thromb Res, 2002; 106: 179-181.

10. Garcia DA, Baglin TP, Weitz JI, Samama MM; American College of Chest Physicians. Parenteral anticoagulants: Antithrombotic Therapy and Prevention of Thrombosis, 9th ed. American College of Chest Physicians Evidence-Based Clinical Practice Guidelines. Chest, 2012; 141 (2 suppl.): e24S-e43S. doi: 10.1378/ chest.11-2291.

11. Greinacher A. Clinical practice. Heparin-induced thrombocytopenia. N Engl J Med, 2015; 373: 252-261. doi: 10.1056/NEJMcp1411910.

12. Kelton JG, Arnold DM, Bates SM. Nonheparin anticoagulants for heparin-induced thrombocytopenia. N Engl J Med, 2013; 368: 737-744. doi: 10.1056/NEJMct1206642.

13. Lubenow N, Hinz P, Thomaschewski S et al. The severity of trauma determines the immune response to $\mathrm{PF} 4 /$ heparin and the frequency of heparin-induced thrombocytopenia. Blood, 2010; 115: 1797-1803. doi: 10.1182/blood-2009-07-231506.

14. Routledge PA, Chapman PH, Davies DM, Rawlins MD. Factors affecting warfarin requirements. A prospective population study. Eur J Clin Pharmacol, 1979; 15: 319-322.

15. Wallace JL, Reaves AB, Tolley EA et al. Comparison of initial warfarin response in obese patients versus non-obese patients. J Thromb Thromb, 2013; 36: 96-101. doi: 10.1007/s11239-0120811-x.

16. Patel JP, Roberts LN, Arya R. Anticoagulating obese patients in the modern era. Br J Haematol, 2011; 155: 137-149. doi: 10.1111/j.1365-2141.2011.08826.x.

17. Pradaxa. Product characteristics.

18. Breuer L, Ringwald J, Schwab S, Köhrmann M. Ischemic stroke in an obese patient receiving dabigatran. N Engl J Med, 2013, $368,25,2440$.

19. Liesenfeld KH, Lehr T, Dansirikul C et al. Population pharmacokinetic analysis of the oral thrombin inhibitor dabigatran etexilate in patients with non-valvular atrial fibrillation from the RE-LY trial. J Thromb Haemostasis, 2011; 9: 2168-2175.

20. Lachant DJ, Uraizee I, Gupta R, Pedulla AJ. Novel oral anticoagulants after gastric bypass surgery: Caveat emptor. Int J Case Reports Images, 2013; 4: 663-665.

21. Eriksson B, Dahl OE, Feuring M et al. Dabigatran is effective with a favourable safety profile in normal and overweight patients un- 
Cardiology Journal 2016, Vol. 23, No. 1

dergoing major orthopaedic surgery: A pooled analysis Thromb Res, 2012; 130: 818-820. doi: 10.1016/j.thromres.2012.07.004.

22. Xarelto. Product characteristics.

23. Kubitza D, Becka M, Zuehlsdorf M, Mueck W. Body weight has limited influence on the safety, tolerability, pharmacokinetics, or pharmacodynamics of rivaroxaban (BAY 59-7939) in healthy subjects. J Clin Pharmacol, 2007; 47: 218-226.

24. Friedman RJ, Hess S, Berkowitz SD, Homering M. Complication rates after hip or knee arthroplasty in morbidly obese patients. Clin Orthop Relat Res, 2013; 471: 3358-3366. doi: 10.1007/ s11999-013-3049-9.

25. Mahlmann A, Gehrisch S, Beyer-Westendorf J. Pharmacokinetics of rivaro rivaroxaban after bariatric surgery: A case report. J Thromb Thrombolysis, 2013; 36: 533-535. doi: 10.1007/ /s11239-013-0891-2.

26. Safouris A, Demulder A, Triantafyllou N, Tsivgoulis G. Rivaroxaban presents a better pharmacokinetic profile than dabigatran in an obese non-diabetic stroke patient. J Neurol Sciences, 2014; 346: 366 .
27. Büller HR, Décousus H, Grosso MA et al. Hokusai-VTE Investigators. Edoxaban versus warfarin for the treatment of symptomatic venous thromboembolism. N Engl J Med, 2013; 369: 1406-1415. doi: 10.1056/NEJMoa1306638.

28. Niebecker R, Jönsson S, Karlsson MO et al. Population pharmacokinetics of edoxaban in patients with symptomatic deepvein thrombosis and/or pulmonary embolism: The Hokusai-VTE phase 3 study. Br J Clin Pharmacol, 2015; 80: 1374-1387. doi: 10.1111/bcp.12727.

29. Product characteristics. Eliquis.

30. Upreti VU, Wang J, Barrett J et al. Effect of extremes of body weight on the pharmacokinetics, pharmacodynamics, safety and tolerability of apixaban in healthy subjects, Br J Clin Pharmacol, 2013; 76: 6.

31. Pathak R, Karmacharya P, Giri S et al. A. Meta-analysis on efficacy and safety of new oral anticoagulants for venous thromboembolism prophylaxis in overweight and obese postarthroplasty patients. Blood Coagul Fibrinol, 2015; 26: 635-642. 